\title{
Clinical trial of community nurse mentoring to improve self-management in patients with chronic obstructive pulmonary disease
}

This article was published in the following Dove Press journal:

International Journal of COPD

3 July 2012

Number of times this article has been viewed

\section{Richard Wood-Baker ${ }^{1}$ \\ David Reid ${ }^{2}$ \\ Andrew Robinson ${ }^{3}$ \\ E Haydn Walters'}

'School of Medicine, University of Tasmania, Hobart; ${ }^{2}$ Department of Respiratory Medicine, Prince Charles Hospital, Brisbane; ${ }^{3}$ School of Nursing \& Midwifery, University of Tasmania, Hobart, Australia
Correspondence: Richard Wood-Baker GPO Box 106I, Hobart,

Tasmania 700I, Australia

Tel +61362227353

Fax +61362227579

Email richard.woodbaker@utas.edu.au
Background: Chronic obstructive pulmonary disease (COPD) impacts on quality of life and is characterized by exacerbations, which increase health care utilization. Developing selfmanagement behaviors of people with COPD is an attractive strategy to reduce exacerbations.

Methods: We investigated the effect of a program to increase self-management behaviors delivered by community health nurses, compared with usual care, on health-related quality of life and health care utilization in people with COPD following hospitalization. Participants were recruited during an admission to hospital and allocated according to domicile. The mentor role was to develop self-management strategies collaboratively over the 12-month study duration. Outcomes included quality of life and health care utilization.

Results: Linear mixed models analyses found a significant benefit in the physical functioning and general health components of the short-form SF-36 questionnaire for the mentored arm, with the average difference between interventions being 5.60 and 4.14, respectively, over 12 months. Survival analysis using a combined endpoint of time to next acute exacerbation requiring rehospitalization or death found a significant benefit favoring the mentored group $(P=0.037)$.

Conclusion: A mentoring program designed to improve self-management behaviors in people with COPD following hospitalization increased some quality of life domains and improved important clinical outcomes.

Keywords: pulmonary disease, chronic obstructive, secondary prevention, quality of life, hospitalization

\section{Introduction}

Chronic obstructive pulmonary disease (COPD) is an overarching term for a group of chronic airway diseases. It is progressive, disabling, and has a high cost for sufferers, their carers, governments, and society in general. ${ }^{1}$ Recent data have shown COPD to be the third leading cause of "burden of disease" in Australia, based on the summary measure of population health, ie, the disability-adjusted life-year. ${ }^{2}$ COPD is the largest contributor to the burden of disease associated with all lung diseases and conditions, ${ }^{3}$ and has a major impact on quality of life and physical activity of those it affects. ${ }^{4}$

With the increasing prevalence of chronic diseases, there has been a move towards developing new paradigms of patient care. Comprehensive cardiopulmonary rehabilitation programs incorporating education and supervised exercise involving a multidisciplinary team are one example. ${ }^{5}$ However, these programs are costly, and the benefits appear to be poorly sustained, ${ }^{6}$ leading to adoption of programs that focus on improving self-management to enhance longer-term health status and reduce hospital admissions. ${ }^{7,8}$ While the content and role of such self-management programs 
in COPD has yet to be defined fully, they clearly need to be more sophisticated than the simple provision of information or instructions. ${ }^{9}$ The failure of simple educational approaches has led to models of care wherein the patient is seen as central to the management of their health, and work in partnership with health care professionals to focus on self-management of their own illness. Such self-management requires a multifaceted approach to change behavior in patients ${ }^{10}$ by augmenting "self-efficacy".

One such model is the chronic disease self-management program, ${ }^{11}$ in which the development of self-efficacy is a core component. ${ }^{12}$ In COPD, self-efficacy in patients has been shown to be related to physical function ${ }^{13}$ and survival, ${ }^{14}$ and may be improved by comprehensive interventions which improve quality of life. ${ }^{15}$ We report on a controlled clinical trial of a community health nurse-led mentoring program, based on principles from the chronic disease self-management program, delivered in conjunction with a symptom diary, in COPD.

\section{Materials and methods Study design}

The study was a controlled clinical trial of mentoring by community health nurses combined with daily diary symptom monitoring, compared with usual care in COPD. Participants were recruited from admissions to the Royal Hobart Hospital, which is both a large general hospital and the tertiary teaching hospital for Southern Tasmania. Admissions with a primary diagnosis of an acute exacerbation of COPD, who lived in the designated catchment areas were enrolled and allocated to an intervention group or a control group according to domicile. Participants in the active arm lived in one of four mentor catchment areas and participants in the control arm living in areas matched for rurality and socioeconomic status. The study was approved by the Human Research Ethics Committee (Tasmania) Network (H8370).

\section{Participants}

Key inclusion criteria were age over 45 years, a smoking history $>10$ pack-years, a post-bronchodilator forced expiratory volume in one second/forced vital capacity $\left(\mathrm{FEV}_{1} /\right.$ FVC) ratio $<0.7$ on spirometry, at least one exacerbation of COPD in the previous 12 months, ability to comply with study requirements (defined as a Mini-Mental score $>21$ in order to complete questionnaires and Internet components) and a home environment capable of computer and telephone access. Key exclusion criteria were a diagnosis of other lung disease, unstable cardiac, renal, or hepatic disease, or an anticipated survival of $<12$ months.

\section{Mentoring}

Mentors were community health nurses recruited from four rural and urban community health centers and employed by the Department of Health and Human Services in Southern Tasmania. Twenty-one community health nurses volunteered to become mentors and each was subsequently allocated a maximum of five patients. Mentors were trained by a health psychologist on the transtheoretical model of change ${ }^{16}$ and concepts of motivational interviewing, ${ }^{17}$ given an update on COPD and its management, and participated in sessions on telephone coaching. Over the course of the project they also participated in monthly reflective feedback meetings to develop strategies to facilitate improved self-management of the research participants. ${ }^{18}$ The community health nurse's role was one of partnership with participants, collaboratively developing self-management strategies over a total of 12 months. One week post-recruitment mentors visited the patient at home for a general assessment, and at a subsequent visit discussed the main clinical or social problem (their main "life" problem) and set a medium-term goal to address it. An "action plan" to move towards achieving the goal was devised, which was behavior-specific, reasonable, measurable, and achievable within a meaningful/pragmatic time frame. Mentors regularly telephoned the client to discuss progress and, if necessary, reformulate the action plan.

\section{Daily diary}

Participants in the intervention arm completed a daily diary that recorded their breathlessness, cough, sputum, wellness, physical activity, and use of reliever medication. They compared symptoms to their preadmission stable state using a seven-point scale, where the mid-point was "no change from usual". Paper diaries were initially provided to the intervention participants with the option of migrating to an electronic (web-based) diary once the mentoring program had become established.

\section{Outcomes}

Outcome assessments were conducted at five visits, ie, baseline, and months 3, 6, 9 and 12. Outcome measures at each assessment included weight, spirometry, health-related quality of life, Hospital Anxiety and Depression score, and the Stanford self-efficacy questionnaire. Health-related quality of life was measured using the SF-36, a multipurpose short-form health survey that yields an eight-scale profile of functional health and well-being scores as well as a psychometrically-based physical and mental health summary. Raw scores were transformed using 1998 US general population norms. The Stanford 
self-efficacy questionnaire is a six-item questionnaire that has been shown to be a valid measure of self-efficacy in subjects with a range of chronic diseases, although little work has been done specifically in COPD. The number of discharge medications and a comorbidity score, the Geriatric Index of Comorbidity, which generates a composite score from the number of diseases and disease severity to give a score of $1-5,{ }^{19}$ were measured at baseline. Data on emergency department attendances and hospital admissions were retrieved directly from the Tasmanian Department of Health and Human Services records. Acute exacerbations of COPD were defined as needing hospitalization for worsening of an individual's respiratory symptoms, usually a combination of breathlessness, cough, and sputum.

\section{Statistical analysis}

Outcome data were recorded electronically or on hard copy and subsequently entered into the study database. Measurements were extracted from the database and entered into SPSS version 18.0 (SPSS Inc, Chicago, IL) for analyses. Comparisons of baseline characteristics between groups were performed using Student's $t$-tests for continuous data and Chi-squared tests for ordinal data. Comparisons of health outcomes between "intervention/treatment" groups were performed using linear mixed models, with visit, $\mathrm{FEV}_{1}$, body mass index, and gender included as covariates. The Kaplan-Meier method was used to generate time to event curves for acute exacerbations and death combined, and differences between groups were tested using the Wilcoxon (Breslow) test.

\section{Results}

We identified 319 consecutive admissions with acute exacerbations of COPD to the hospital over 16 months between August 2005 and November 2006. Of these, $105(33 \%)$ did not fulfill the inclusion and exclusion criteria, most commonly due to a low Mini-Mental score, with a further $63(20 \%)$ declining to participate (Figure 1). The 106 participants recruited into the study were elderly and predominantly urban dwelling (Table 1). The mean FEV was $<40 \%$ predicted, and Global Initiative for Chronic Obstructive Lung Disease (GOLD) classification showed that 17 participants (16\%) had stage II, 49 (46\%) had stage III, and $39(37 \%)$ had stage IV disease. Participants were above the ideal weight range and were unlikely to have achieved higher levels of education. Following allocation by place of residence, there were 55 participants in the mentored and 51 in the control arm.

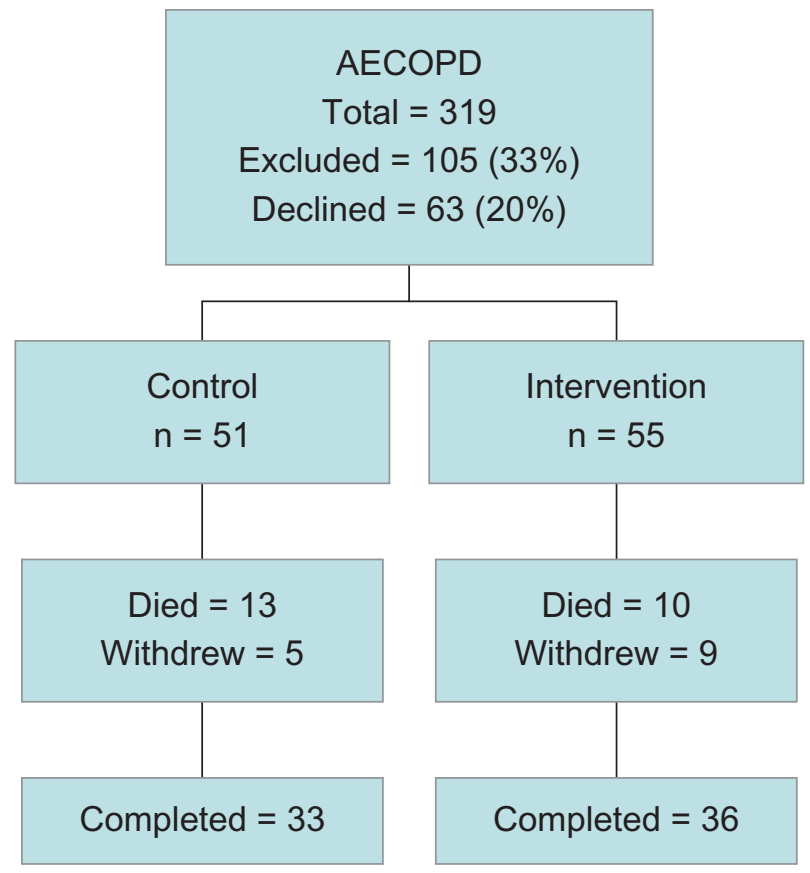

Figure I Flow diagram of participant progress through the study. Abbreviation: AECOPD, acute exacerbations of chronic obstructive pulmonary disease.

Baseline characteristics of the groups were similar in terms of age, body mass index, $\mathrm{FEV}_{1}$ (expressed as a percentage of predicted), marital status, and educational level, but there were significantly more females in the mentored group. During the study, 14 (13\%) withdrew, mainly for personal reasons related to the burden of study participation.

There were 90 episodes (range 0-7 per participant) of hospitalization over the 12 months prior to the index admission and the level of functional impairment at recruitment was high, whether measured as Medical Research Council dyspnea score or quality of life (Table 2). According to SF-36 scales, the physical and mental component summaries were lower than for the normalized population at baseline, with impairment seen across physical and emotional scales.

Table I Participant demographics

\begin{tabular}{lllll}
\hline & All subjects & Control & Mentored & P value \\
\hline Total number & 106 & $5 \mathrm{I}$ & 55 & \\
Female gender (\%) & 57 & 45 & 67 & 0.03 \\
Age (years) & $69.1 \pm 9.7$ & $69.7 \pm 9.4$ & $66.5 \pm 9.5$ & 0.80 \\
Percent & $34.3 \pm 13.9$ & $33.8 \pm 13.6$ & $34.9 \pm 14.2$ & 0.69 \\
predicted FEV ${ }^{*}$ & & & & \\
Body mass & $26.4 \pm 7.2$ & $27.8 \pm 7.1$ & $25.2 \pm 7.4$ & 0.07 \\
index (kg/m²) & & & & \\
Rural (\%) & 27 & 27 & 27 & 1.00 \\
Single (\%) & $5 \mathrm{I}$ & 53 & 49 & 0.70 \\
Education $>$ & 20 & 22 & 20 & $0.8 \mathrm{I}$ \\
YI0 (\%) & & & & \\
\hline
\end{tabular}

Note: *Mean \pm standard deviation.

Abbreviation: $\mathrm{FEV}_{1}$, forced expiratory volume in one second. 
Table 2 Baseline outcome measures

\begin{tabular}{|c|c|c|c|}
\hline Outcome & Control & Mentored & $P$ value \\
\hline MRC dyspnea score & $3.7 \pm 1.1$ & $3.4 \pm 1.1$ & 0.99 \\
\hline Hospital anxiety score & $8.8 \pm 5.0$ & $9.8 \pm 4.7$ & 0.30 \\
\hline Hospital depression score & $7.3 \pm 3.6$ & $6.7 \pm 3.9$ & 0.44 \\
\hline SF36 physical function & $24.8 \pm 9.0$ & $26.7 \pm 8.6$ & 0.27 \\
\hline SF36 role physical & $30.7 \pm 11.1$ & $29.2 \pm 8.4$ & 0.40 \\
\hline SF36 bodily pain & $40.3 \pm 15.8$ & $41.2 \pm 12.9$ & 0.74 \\
\hline SF36 general health & $30.2 \pm 11.1$ & $30.9 \pm 9.0$ & 0.73 \\
\hline SF36 vitality & $38.4 \pm 10.5$ & $38.7 \pm 11.4$ & 0.90 \\
\hline SF36 social functioning & $33.5 \pm 14.7$ & $33.7 \pm 12.6$ & 0.94 \\
\hline SF36 role emotional & $28.7 \pm 16.8$ & $26.5 \pm 12.2$ & 0.45 \\
\hline SF36 mental health & $41.6 \pm 14.3$ & $37.6 \pm 11.2$ & 0.11 \\
\hline $\begin{array}{l}\text { SF36 physical component } \\
\text { summary }\end{array}$ & $30.2 \pm 7.8$ & $32.3 \pm 7.5$ & 0.17 \\
\hline $\begin{array}{l}\text { SF36 mental component } \\
\text { summary }\end{array}$ & $38.8 \pm 14.3$ & $36.1 \pm 11.2$ & 0.28 \\
\hline Stanford self-efficacy score & $5.19 \pm 2.5$ & $5.40 \pm 2.41$ & 0.68 \\
\hline
\end{tabular}

Abbreviation: MRC, Medical Research Council.

Eighty-six percent of participants were discharged on over six medications (mean 9, range 1-15), but there was no significant difference between groups for this or the comorbidity index. The average Hospital Anxiety and Depression score reflected poor mental health, both control and mentored groups having higher average levels of anxiety than depression. Using a cutpoint of 11 or higher to define caseness, ie, the probability of clinical disease, ${ }^{20} 15 \%$ of participants had clinical depression and $43 \%$ had clinical anxiety at baseline.

For most outcomes across breathlessness, anxiety, depression, self-efficacy, and health-related quality of life, there was no statistically significant difference between interventions over time (visit, Table 3). However, there was a significant effect on the SF-36 physical functioning component for both intervention and $\mathrm{FEV}_{1}$ and for intervention alone on general health. For both physical functioning and general health, there was a statistically significant benefit of allocation to the mentored arm; the average difference at 12 months was 5.60 for physical functioning and 4.14 for general health.

Readmission to hospital was common. In the control arm, $67 \%$ of participants were readmitted with a total of 107 hospital admissions, and in the mentored arm $62 \%$ of participants were readmitted with a total of 110 admissions, but there was no significant difference between the groups. Twenty-three (22\%) participants died during the study; 11 died from respiratory causes (eight COPD, two lung cancer, and one pneumonia), three from cardiovascular causes, two from miscellaneous causes (one bleeding gastric ulcer, one mesenteric ischemia), and the cause was unknown in eight patients. Because acute exacerbations and mortality
Table 3 Effect of mentoring on mental health, quality of life, and dyspnea

\begin{tabular}{llll}
\hline Outcome measure & \multicolumn{2}{l}{ Change per visit* } & P value \\
\cline { 2 - 3 } & Control & Intervention & \\
\hline Hospital depression score & 0.32 & 0.13 & 0.379 \\
Hospital anxiety score & -0.71 & -0.91 & 0.393 \\
SF36 physical functioning & -1.48 & -0.08 & 0.005 \\
SF36 role physical & 1.32 & 1.93 & 0.816 \\
SF36 bodily pain & -1.73 & 0.99 & 0.139 \\
SF36 general health & 0.42 & 1.46 & 0.046 \\
SF36 vitality & 2.79 & 2.56 & 0.689 \\
SF36 social functioning & 2.79 & 2.41 & 0.662 \\
SF36 role emotional & 3.14 & 2.20 & 0.330 \\
SF36 mental health & 2.22 & 3.27 & 0.118 \\
SF36 physical component & -1.42 & -0.49 & 0.055 \\
summary & & & \\
SF36 mental component & -131.7 & -187.0 & 0.718 \\
summary & & & \\
MRC functional dyspnea & 0.35 & 0.28 & 0.349 \\
score & & &
\end{tabular}

score

Note: *Interval between visits was 3 months.

Abbreviation: MRC, Medical Research Council.

are major and serious outcomes for patients with CPOD, we combined these for analysis. The Kaplan-Meier survival curves for this combined endpoint are shown in Figure 2. There was a significant difference between arms for the combined endpoint $(P=0.037)$ favoring the mentored group, although by the end of the study approximately $50 \%$ of both arms had either died or been rehospitalized.

\section{Discussion}

We report on the outcomes of a controlled trial of a mentoring program delivered by community health nurses using a combination of home visits and telephone follow-up to develop self-management strategies collaboratively for people hospitalized with COPD. This is a novel approach to the management of COPD in the community, using a resource (community health nurses) widely available in Australia and a delivery method (telephone) that is widely applicable to our dispersed population. This simple approach, which is far less intensive than traditional pulmonary rehabilitation, significantly improved aspects of health-related quality of life and reduced the combined endpoint of death or readmission when compared with usual community care. These benefits were seen despite only $47 \%$ of the screening population entering the study.

We found a significant improvement in health-related quality of life across a limited number of the SF-36 scales, with no significant difference between interventions for most scales or summary scores. The greatest improvement in health-related quality of life was seen for physical 


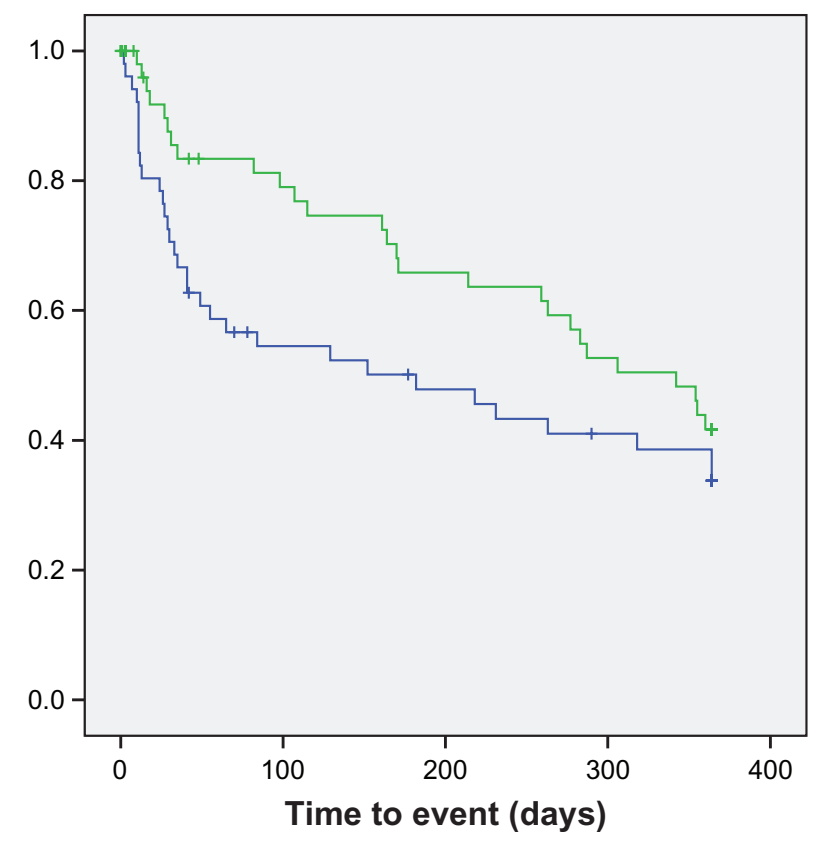

Figure 2 Effect of mentoring on death and readmission combined. Notes: Green, control group; Blue, intervention group.

functioning, which is an indication of the extent to which, on a typical day, a person is limited by their health in performing a range of physical activities, including bathing and dressing. Our participants had decreased baseline physical functioning compared with the Australian population, ${ }^{21}$ with a mean score of 26.1 compared with the comparative Australian general population score when aged 56-74 years of 67.5. Over the 12 months of the study, there was an average benefit of 5.6 points in physical functioning in the mentored arm compared with the usual care arm. This change is larger than physicians had estimated a single state change within the physical functioning scale to be (a change in score of 5), but less than a small clinically important difference (change in score of 10). ${ }^{22}$ Patients with COPD appear to have a different perspective from physicians, and would rate the average change achieved over the 12 months of the study as being a moderate to large improvement (small or moderate improvement $=5$, large improvement $=6) .{ }^{23}$

The general health scale, which combines self-assessed health status with indicators of current expectations and perceptions of health relative to the health of others, also showed a significant change over the study favoring the mentored arm. At recruitment, our participants also had a substantially decreased general health mean score compared with the comparative Australian population, with a mean score of 30.1 compared with 61.2. Over the 12-month study period, there was an overall benefit of 4.16 in the mean general heath score for the mentored group. This change is smaller than physician estimates for a stage change or small clinically important difference, ${ }^{22}$ but would be rated as a small to moderate improvement by patients ( small $=3$, moderate $=1$, large $=11){ }^{23}$

Although these improvements in health-related quality of life are small, they indicate a benefit from the telephone mentoring to support behavioral change. This benefit is in contrast with interventions in heart failure, another high-burden chronic cardiopulmonary disease in Western communities, which have failed to show any such benefit. A randomized trial of a disease management program delivered by nurses in patients with congestive heart failure in Texas found that participants allocated to active intervention tended to experience only a short-term improvement in SF-36 scales during the first 6 months of the study, but with a subsequent deterioration and no significant difference compared with controls at any time point. ${ }^{28}$ A second study of a 15 -week behavioral management program in mild heart failure also failed to find any significant benefit compared with usual care in SF-36 summary scores for physical or mental functioning, although it did find a significant benefit for disease specific health-related quality of life measured by the Minnesota Living with Heart Failure Questionnaire. ${ }^{24}$ Other studies in COPD do support our findings of an improvement in healthrelated quality of life from a program to improve patient capacity for self-management, although there have been a range of findings, including no benefit. A systematic review of self-management in $\mathrm{COPD}^{25}$ found an improvement for the St George's Respiratory Questionnaire total (weighted mean difference $-2.58 ; 95 \%$ confidence interval $-5.14,-0.02$ ) and impact scores (weighted mean difference $-2.83 ; 95 \%$ confidence interval $-5.65,-0.02)$ that reached statistical significance at the $5 \%$ level, but did not reach the clinically relevant improvement of four points. Previous studies using the SF-36 to measure health-related quality of life have not found any significant difference between nurse-led interventions and usual care. ${ }^{26,27}$

As well as improvement in quality of life, we found a benefit for mentoring in the combined outcome of time to readmission or death, ie, major outcomes that were combined to improve power for such events. When other studies are combined, they have shown a statistical benefit in the reduction in hospital admissions for self-management, ${ }^{25}$ although this is largely due to two studies, ${ }^{7,27}$ with other studies not finding a significant benefit. These positive studies involved substantial face-to-face contact with health professionals, which is more difficult for poorly mobile patients with COPD, compared with our telephone mentoring approach. 
We found no difference between the groups for either the total number of hospital admissions (mentored $=110$ admissions for 34 participants, control $=107$ admissions for 33 participants), although there was a saving of 2.0 bed days per participant in the intervention group. This reduction in length of hospital stay may reflect the increased support provided to the intervention group through their mentors following discharge into the community. Community support following hospital discharge may be an important factor in readmission, and would help explain the positive effect found by Rea et al, ${ }^{27}$ where a respiratory nurse specialist visited participants in the intervention group at home following discharge.

The benefits in health-related quality of life and time to death or readmission found in our study are promising for the use of mentoring to support people with COPD, but there are weaknesses in the findings. Due to organizational constraints, we were not able to use a randomized study design and participants were allocated according to place of residence. While we attempted to match localities in terms of socioeconomic attributes, it is possible that there were inequalities in these aspects eg, education levels, between the study arms. Furthermore, we did not recruit the numbers we had anticipated, largely because only $33 \%$ of potential participants identified entered the study. Based on initial power calculations, we set a recruitment target of 200 participants, but failed to achieve that and the lower numbers enrolled could have impacted on the power of the study to find differences between interventions. It is reassuring that we did find significant differences in some outcomes, and while the reduced numbers may impact on generalizability of the findings, they do not appear to have resulted in a negative outcome from a type 2 statistical error. The main reason for failure to enter the study was poor cognitive ability, which is perhaps inevitable in the age group involved and does need to be taken into account in scaling up such a program for the whole community. Reassuringly, once enrolled, there was no differential dropout rate between the arms, with $65 \%$ completing the study in both arms, despite the impost of the mentoring program.

In conclusion, we found that a novel mentoring program designed to improve self-management behaviors in people with COPD following hospitalization, and delivered by community health nurses through a combination of home visits and telephone calls, was effective in increasing some quality of life domains and the time to death or readmission. These data provide further evidence that community interventions designed to facilitate behavioral change are effective in improving quality of life and reducing health care utilization in selected people with chronic disease. However, before widespread adoption of such an intervention, it would be important to undertake an economic analysis of the cost of the benefits seen from the mentoring program.

\section{Acknowledgments}

The investigators would like to acknowledge the contribution of the community health nurses who provided the mentoring program and the patients with COPD who participated in the study. Thanks also to Helen Courtney-Pratt for her work in coordinating and supporting the mentors, and to Emma Lee, Sally Bennett, and Elisabeth Hammer for enrolment and data collection. The Pathways Home for Respiratory Illness project was supported by the Tasmanian Department of Health and Human Services and funded by the Commonwealth Department of Health and Aging through the Australian Health Care Agreement 2005.

\section{Disclosure}

The authors report no conflict of interest in this work.

\section{References}

1. McKenzie DK, Frith PA, Burdon JG, Town GI. The COPDX plan: Australian and New Zealand guidelines for the management of chronic obstructive pulmonary disease 2003. Med J Aust. 2003; 178 Suppl:S7-S39.

2. Mathers CD, Vos ET, Stevenson CE, Begg SJ, Turrell G, Mathers C. The burden of disease and injury in Australia. Socioeconomic inequalities in all-cause and specific-cause mortality in Australia: 1985-1987 and 1995-1997. Bull World Health Organ. 2001;79(11):1076-1084.

3. Australian Lung Foundation. Economic impact of COPD and cost effective solutions. Access Economics Pty Limited; 2008. Available from: http://www.lungfoundation.com.au/images/stories/docs/copd/2008_alf_ access_economic_impact_report.pdf. Accessed May 15, 2012.

4. McGlone S, Venn A, Walters EH, Wood-Baker R. Physical activity, spirometry and quality of life in chronic obstructive pulmonary disease. COPD. 2006;3(2):83-88.

5. Lacasse Y, Brosseau L, Milne S, et al. Pulmonary rehabilitation for chronic obstructive pulmonary disease. Cochrane Database Syst Rev. 2002;3:CD003793.

6. Ries AL, Kaplan RM, Myers R, Prewitt LM. Maintenance after pulmonary rehabilitation in chronic lung disease: a randomized trial. Am J Respir Crit Care Med. 2003;167(6):880-888.

7. Bourbeau J, Julien M, Maltais F, et al. Reduction of hospital utilization in patients with chronic obstructive pulmonary disease: a diseasespecific self-management intervention. Arch Intern Med. 2003;163(5): 585-591.

8. Casas A, Troosters T, Garcia-Aymerich J, et al. Integrated care prevents hospitalisations for exacerbations in COPD patients. Eur Respir J. 2006;28(1):123-130.

9. Wood-Baker R, McGlone S, Venn A, Walters E. Written action plans in chronic obstructive pulmonary disease increase appropriate treatment for acute exacerbations. Respirology. 2006;11(5):619-626.

10. Bourbeau J, Nault D, Dang-Tan T. Self-management and behaviour modification in COPD. Patient Educ Couns. 2004;52(3):271-277.

11. Lorig KR, Sobel DS, Ritter PL, Laurent D, Hobbs M. Effect of a selfmanagement program on patients with chronic disease. Eff Clin Pract. 2001;4(6):256-262. 
12. Bandura A, Adams NE, Beyer J. Cognitive processes mediating behavioral change. J Pers Soc Psychol. 1977;35(3):125-139.

13. Arnold R, Ranchor AV, DeJongste MJL, et al. The relationship between self-efficacy and self-reported physical functioning in chronic obstructive pulmonary disease and chronic heart failure. Behav Med. 2005;31(3):107-115.

14. Kaplan RM, Ries AL, Prewitt LM, Eakin E. Self-efficacy expectations predict survival for patients with chronic obstructive pulmonary disease. Health Psychol. 1994;13(4):366-368.

15. Scherer YK, Schmieder LE. The effect of a pulmonary rehabilitation program on self-efficacy, perception of dyspnea, and physical endurance. Heart Lung. 1997;26(1):15-22.

16. Prochaska JO, DiClemente CC, Norcross JC. In search of how people change. Applications to addictive behaviors. Am Psychol. 1992;47(9): 1102-1114.

17. Miller WR, Rollnick S. Ten things that motivational interviewing is not. Behav Cogn Psychother. 2009;37(2):129-140.

18. Robinson A, Courtney-Pratt H, Lea E, et al. Transforming clinical practice amongst community nurses: mentoring for COPD patient self-management. J Clin Nurs. June 16, 2008. [Epub ahead of print.]

19. Rozzini R, Frisoni GB, Ferrucci L, et al. Geriatric Index of Comorbidity: validation and comparison with other measures of comorbidity. Age Ageing. 2002;31(4):277.

20. Snaith RP. The Hospital Anxiety and Depression Scale. Health Qual Life Outcomes. 2003;1(29):29.

21. Trewin D. National Health Survey: SF36 Population Norms, Australia. Canberra, ACT: Australian Bureau of Statistics; 1995.
22. Wyrwich KW, Tierney WM, Babu AN, Kroenke K, Wolinsky FD. A comparison of clinically important differences in health-related quality of life for patients with chronic lung disease, asthma, or heart disease. Health Serv Res. 2005;40(2):577-591.

23. Wyrwich KW, Metz SM, Kroenke K, Tierney WM, Babu AN, Wolinsky FD. Measuring patient and clinician perspectives to evaluate change in health-related quality of life among patients with chronic obstructive pulmonary disease. J Gen Intern Med. 2007;22(2): 161-170.

24. Shively M, Kodiath M, Smith TL, et al. Effect of behavioral management on quality of life in mild heart failure: a randomized controlled trial. Patient Educ Couns. 2005;58(1):27-34.

25. Effing T, Monninkhof EM, van der Valk PD, et al. Self-management education for patients with chronic obstructive pulmonary disease. Cochrane Database Syst Rev. 2007;4:CD002990.

26. Coultas D, Frederick J, Barnett B, Singh G, Wludyka P. A randomized trial of two types of nurse-assisted home care for patients with COPD*. Chest. 2005;128(4):2017-2024

27. Rea H, McAuley S, Stewart A, Lamont C, Roseman P, Didsbury P. A chronic disease management programme can reduce days in hospital for patients with chronic obstructive pulmonary disease. Intern Med $J$. 2004;34(11):608-614.

28. Smith B, Forkner E, Zaslow B, Krasuski RA, Stajduhar K, Kwan M, Ellis R, Galbreath AD, Freeman GL. Disease management produces limited quality-of-life improvements in patients with congestive heart failure: evidence from a randomized trial in community-dwelling patients. Am J Manag Care. 2005 Nov;11(11):701-13.
International Journal of COPD

\section{Publish your work in this journal}

The International Journal of COPD is an international, peer-reviewed journal of therapeutics and pharmacology focusing on concise rapid reporting of clinical studies and reviews in COPD. Special focus is given to the pathophysiological processes underlying the disease, intervention programs, patient focused education, and self management protocols

\section{Dovepress}

This journal is indexed on PubMed Central, MedLine and CAS. The manuscript management system is completely online and includes a very quick and fair peer-review system, which is all easy to use. Visit http://www.dovepress.com/testimonials.php to read real quotes from published authors. 